\title{
IT Governance and Benefit Models: Literature Review and Proposal of a Novel Approach
}

\author{
Amit Ghildyal*, Elizabeth Chang \\ UNSW Canberra, ACT, 2601. \\ * Corresponding author. Email: Amit.Ghildyal@student.adfa.edu.au \\ Manuscript submitted December 10, 2016; accepted April 5, 2017. \\ doi: 10.17706/ijeeee.2017.7.2.123-131
}

\begin{abstract}
The benefits framework has been widely discussed in recent literature for IT governance. This paper discusses existing IT governance and benefit models, and the issues with their implementation for benefits realization. The paper proposes a novel approach to benefits realization using defuzzification, stratification, target reachability and incremental enlargement principle within an iterative innovation-loop.
\end{abstract}

Key words: Benefit models, benefit management, benefit realization, IT governance.

\section{Introduction}

The rapid development of information technologies, infrastructure networks, and social media is affecting all areas of enterprise governance. With regard to corporate IT governance, there are several IT risks which hinder enterprise performance. These include issues, such as 1) staff unable to access integrated data due to multiple disconnected systems; 2) proliferation of manual based-systems; 3) lack of semantic integration; 4) very limited scope for obtaining a snapshot of data from multiple systems. Therefore, the research in this paper examines the literature in IT Governance and proposes a benefits realisation framework for IT governance.

The paper is organised as follows: Section 2 explains the issues related with IT governance models. Section 3 is dedicated to the literature review of IT Governance models. Key challenges of Benefit models are explained in Section 4. The proposed de-fuzzification of the Benefit model is discussed in Section 5.

\section{Background}

IT governance represents a structural relationship between different processes and mechanisms through effective and efficient use of IT strategy, and resources that can be controlled on demand with a view to achieving the goals and objectives of an enterprise. It is, in actual fact, a combination of processes that reduces the related risks through controlling IT investments and return aspects in order to add value to an organization's performance. IT governance of an enterprise is the responsibility to ensure the enterprise's strategies and objectives through building IT models under the broad directions of directors and executive managers. In a broader sense, "IT governance encompasses developing the IT strategic plan, assessing the nature and organizational impact of new technologies, developing the IT skill base, aligning IT direction and resources, safeguarding the interests of internal-external IT stakeholders as well as taking into account the quality of relationships between stakeholders". [1]

Various studies support the initiatives of IT Governance in the public sector by analysing the performance 
of IT investments and corporates [2], [3], and [1]. However, there are issues that hinder the implementation of practical IT governance. These issues lead to frequent problems such as staff's inability to access integrated data due to multiple disconnected systems, propagation of manual based-systems, lack of semantic integration and very limited scope for obtaining a snapshot of data from multiple systems. Here, the issues with implementation of IT governance result in the enterprise having no single source of accurate information.

IT governance of an enterprise aims to develop, direct and control IT strategy and resources in order to achieve enterprise's goals and objectives by structuring the relationship of different interlinked processes and mechanisms. It is defined as a set of processes that can not only add value to an organization, but also balance the risk and return values associated with IT investments. However, as corporate governance is not being used we face with IT governance problems.

\section{IT Governance Models}

A number of IT governance models are developed with an intention to increase IT efficiency, reduce IT costs and increase control of IT investments both in private and public sectors. Among these, the most popular models are ITIL, COBIT, ISO17799 which can provide guidance and tools for better IT governance.

CoBIT Model: This model is the most popular model developed by the Information Systems Audit and Control Association (ISACA). Basically, this model provides the basic guidelines and supporting toolset for IT governance. In this model, there is an option for auditors and companies to integrate technology and implement controls in order to meet specific business objectives. CoBIT 5 is the latest version which was released in 2012. The main focus of CoBIT is to mitigate risk and uphold the business objectives by providing a set of recommended best practices for governance and control process of information systems and technology. The underpinning concept of the COBIT framework is that IT should be controlled by concentrating on information that is needed to support the business objectives and requirements. The required information is the result of combined application of IT-related resources and IT processes. [4]. CoBIT model has three components [4], namely: information criteria, IT resources and IT processes. Here, information criteria is measured by the effectiveness, efficiency, confidentiality, integrity, availability, compliance and reliability; and IT resources are the people, applications, technology, facilities and data.

Issues with CoBIT Model: There are some existing problems in CoBIT model [4] such as:

1) Complicated concepts and structure.

Researchers and managers came across to inform that COBIT model is a bit complex to understand. The single document COBIT4.1 includes:

- Framework: it provides a detail explanation of how COBIT organizes IT governance, management and control objectives and good practices by IT domains and processes, and links them to business requirements;

- Control Objectives: provides good management practice objectives for IT processes;

- Management Guidelines: provides tools to help assign responsibility, measure performance, and benchmark and address gaps in capability;

- Maturity Model: provides profiles of IT processes describing possible current and future states.

It requires a great deal of time learning all its concepts and tools. For example, only for the Control Objectives, there are 34 IT processes with 222 control objectives and more than 300 KPIs and KGIs, and overwhelming experience for most people. It is difficult to capture the essence of COBIT quickly by even experienced people.

2) Lack of implementation guidance and proven benefits.

Due to the complex architecture, it is difficult for organizations to understand and use it. There are no concrete methods or guidelines to facilitate the customization to specific environment. In addition, the 
value of CoBIT is hard to perceive because there are no proven statistics or studies confirming its claimed advantages. In contrast, other programs such as ITIL and ISO27000 provide more significant values.

ITIL Model: Information Technology Infrastructure Library (ITIL) is a model of IT governance which can be used for both public and private sectors. The main objective of this model is to deliver high quality IT services, essentially for IT Service Management (ITSM). ITIL views IT Service Management (ITSM) as a lifecycle of 5 phases: 1) Service Strategy 2) Service Design. 3) Service Transition, 4) Service Operation, and 5) Service Improvement. ITIL is a good fit for organizations concerned about operations.

Benefits and Issues with ITIL Model: There are many benefits of using ITTL model such as cost savings, risk management and streamlining of IT operations [5], [6]. Like other model, it also faces several implementation challenges. The simple facts are that ITIL isn't for everyone, everyone doesn't need everything in the ITIL, you can't use what ITIL says verbatim, and you cannot create an organization around ITIL [5]. Regardless of its advantages, ITIL provides only basic guidelines. There is no detailed instruction to use this model. Shang and Lin [6] described the downsides of ITIL through multi-case study. The drawbacks are: 1) incongruence between quality improvement and customer's expectation, 2) ineffectiveness in meeting customer's demands, 3) conflicts between standardized processes and unanticipated requests, 5) lack of autonomy and calcified learning scope, and 6) people lacking integrative capability. The authors also summarized the issues for implementing the ITIL model as shown in the Table 1.

Table 1. Problems of ITIL Model [6]

\begin{tabular}{|c|c|c|c|c|c|}
\hline & Issue for Implementing ITIL & Financial & Customer & $\begin{array}{l}\text { Internal } \\
\text { Process }\end{array}$ & $\begin{array}{l}\text { Learning/ } \\
\text { Growth }\end{array}$ \\
\hline 1 & $\begin{array}{l}\text { Dissatisfied customers / due to the gap between the degree of } \\
\text { improved service quality and customers' perception }\end{array}$ & & $\sqrt{ }$ & & \\
\hline 2 & Unable to satisfy customers' specific needs in time & & $\sqrt{ }$ & & \\
\hline 3 & Extra costs/ occurred in education and management & $\sqrt{ }$ & & & \\
\hline 4 & $\begin{array}{c}\text { Time lag /between investment in ITIL project and performance } \\
\text { outcome }\end{array}$ & $\sqrt{ }$ & & $\sqrt{ }$ & \\
\hline 5 & $\begin{array}{l}\text { Conflicts/ between urgent needs for quality improvement and } \\
\text { cost consideration }\end{array}$ & $\sqrt{ }$ & & $\sqrt{ }$ & \\
\hline 6 & Difficulties in implementation & & & $\sqrt{ }$ & \\
\hline 7 & Employee resistance & & & & $\sqrt{ }$ \\
\hline 8 & Lack of integration ability & & & & $\sqrt{ }$ \\
\hline
\end{tabular}

COSO: This model is proposed by the Committee of Sponsoring Organizations of the Treadway Commission (COSO) for evaluating internal controls. It includes guidelines on many functions, including human resource management, inbound and outbound logistics, external resources, information technology, risk, legal affairs, the enterprise, marketing and sales, operations, all financial functions, procurement and reporting. Though this model is a more business-general model, it has less IT-related functions in comparison to others.

Issues with COSO Model: There are some existing problems in COSO model. The problems are identified by Leitch [7].

- Gaps in control objectives: The COSO matrices are based on abstract models of business processes with no concrete details about the systems or people involved. There is massive scope for missing 
controls within this model and even this is not noticeable on the COSO matrices. Beyond this, there is no consistent model by which the objectives are derived and which gives assurance that the objectives are complete.

- No usable list of controls. Controls are noted on the matrix, but not all controls are presented and not just once. Sometimes there exists redundancy of controls because many controls will appear more than once. In practice, it is common to find that the same control appears with different wording. It is not easy to handle duplication within this model.

- Systematic understatement of controls. The duplication de-motivates people from writing down a control whenever it applies to an objective/risk. Consequently, the control requirements are not fully stated. This in turn makes control systems to be multi-layered across many control objectives.

- Gaps in controls. In this model, there are many controls which are neither mentioned at all. These controls absence may also not be visible.

CMMI: A group from government, industry and Carnegie-Mellon's Software Engineering Institute created a model called "Capability Maturity Model Integration (CMMI)". There are 22 process areas within this model which are categorized into appraisal, evaluation and structure. The objectives of CMMI are to help organization with application development, lifecycle issues and improve the delivery of products throughout the lifecycle. Business goals of CMMI model is achieved through a mature process on different areas for interested organization. The different process includes development, acquisition and services etc. There are many benefits of using CMMI model such overall cost savings, predictability in meeting schedules, improvements in quality, improved customer satisfaction and positive returns on investment [8].

Issues with CMMI Model: CMMI is a generic model which does not cover safety engineering aspects such as specialised safety processes, skills, techniques and competencies.

However, the Australian Defence Materiel Organization (DMO) have generated an extension (+SAFE) to the CMMI along two process areas that are able to provide an explicit and focused basis for appraising or improving an organisation's capabilities for providing safety critical products [9], [10]. There are some existing problems in CMMI model ; CMMI model can provide the required efforts for improving the process but it does not provide the detailed implementation process. It indicates what to do but does not show how to do. Another issue with the CMMI model is the complexity for making improvement to organizational internal structure through process development. The identified problems of IT Governance models are summarized in Table 2.

Table 2. Problems with Various IT Governance Models

\begin{tabular}{|c|c|c|}
\hline Models & References & Identified Problems \\
\hline CoBIT & Zhang and Le [4] & $\begin{array}{c}\text {-Complicated concepts and structure } \\
\text { - Lack of Implementation guidance }\end{array}$ \\
\hline ITIL & Marquis [5] & $\begin{array}{r}\text { - Incongruence between quality improvement and customer's expectation } \\
\text {-Inefficiency in meeting customer's needs } \\
\text {-Conflicts between standardized processes and unanticipated requests } \\
\text {-Lack of autonomy and calcified learning scope } \\
\text {-Lacking integrative capability }\end{array}$ \\
\hline COSO & Leitch [7] & $\begin{array}{c}\text {-Gaps in control objectives } \\
\text {-No usable list of controls }\end{array}$ \\
\hline CMMI & Dale and Anderson [10] & -Systematic understatement of controls \\
& & -Gaps in controls \\
\hline
\end{tabular}

\section{Benefit Models and Challenges in Adoption}


Weill and Ross [11] state that executives often feel frustrated, insecure, bewildered, and even angry about the high cost of IT and its limited measurable benefits. According to Weil and Ross, information and IT are the least understood as the key assets for the enterprise and those enterprises govern IT by default more often find that IT sabotages business strategy.

Given that IT governance by default will give limited measurable benefits, the authors reviewed the process models of benefits management. One of the models is proposed by Ward, Taylor [12]. This process model of benefits management provides a basic guideline for benefit management along multiple iterative processes. The process includes identifying and structuring benefits, planning benefits realization, executing the benefits realization plan, evaluating and reviewing results, and assessing potential for further benefits.

Our research finds that the key challenge is to identify the benefit. The questions would include:

- Who (supplier or buyer) will be best to define the benefit?

- Who will be the subject matter expert in the context of business or operation to identify the benefit?

- Who will be the IT expert within or outside the enterprise to help define the benefit?

Remenyi and Sherwood-Smith [13] proposed an Active Benefit Realisation (ABR) process for realizing business benefits from IT systems enabling improved IT governance. They proposed a distinctive approach by including stakeholders to play a co-evolutionary role in the development of information systems in order to focus on business benefits rather than just on information technology. Theirs is a continuous evaluation approach to management of information systems' development, including a feedback loop of following processes: initialisation of the project, production of a picture, agreement to proceed, system development, evidence collection, review and learning and development of updated pictures, including future maintenance project and abandon project.

IT governance process focuses on project management as a means of identifying, defining, monitoring and delivering business benefits as a result of an information system development opportunity. Remenyi and Sherwood-Smith [13] state that through a high degree of openness with information systems professionals playing a co-evolutionary role with line managers and users, as well as financial staff and sometimes customers and other sponsors, more effective information systems may be developed. Central to this collaboration is the inclusion of a feedback loop which will allow appropriate interventions to take place during information systems development and management, leading to a much higher degree of information systems success.

One of key issues of adopting a benefits approach to IT governance is that organisations often have limited understanding of the benefits, including:

- Who will be the subject matter expert (business expert or IT expert or strategist etc.) to define the benefit?

- The accountability of the benefit realisation - who is responsible.

- The expert to measure benefit from IT investment and deliverables in-line with enterprise goals.

- fuzzifiyng of the concept of benefits by definging the right member ship function along with its parmeters so that the whole organisation can understand and appreciate the IT investment and take over.

\section{Defuzzification for Benefit Realization}

We propose a two-step approach to defuzzification of the concept of benefits so that the enterprise can understand and support IT governance and IT investment.

Step 1: Defuzzify the "Benefit" in the benefit model. An example of "Benefits" as defined in the IT governance model is "effectiveness, responsiveness, efficiency, to deliver enterprise-wide information management"[14]; another example with regard to benefits of industry engagement is more commercially aware execution strategies, more innovative solutions, more efficient tendering processes etc. and the benefits 
will be improving certainty, capability, reducing cost etc. The key approach here is to assist the enterprise understand and realize the importance of the "Benefit" model through direct observable or measurable phenomena.

Step 2: Foster "benefits" realization. A large volume of research has been done on IT governance and benefits realisation framework [1-8, 10,11], [10,11], [15-17], [18], [19-22], [23], [24, 25]. Whilst some of this research is focused on the benefit definition from procurement contracting perspective, others are focused on driving knowledge, on continuous benefit realisation review process, the benefit management of information systems, the benefit-strategy-solution mapping, the benefit of IT and R\&D, the benefit of IT and Business alignment, etc.

One of the key steps here is how to foster the linkage between benefit providers and benefit recipients so that it can foster benefit realisation for all parties involved. The research team at UNSW has constructed an innovation-driven benefit management and target realisation framework that will encompass two parts:

Part I: to help understand and realise the "Benefit" construct though "stratification, target reachability and incremental enlargement principle [26].

In computational systems, we define the "benefit" as the target outcome, "benefit realisation" as the target. We define "target" as "a set of targets", and we define "target reachability" as moving or transitioning from "current state pressure" to a target state "the Future State" in minimum steps [modal logic].

Refer Fig. 1 "Strata" S is defined around the "Target set" T. A Strata may be a special group, a coalition, a layer perceptron, or a sub-system with a stratified structure that is underpinned by temporary joint and agreed goals or target set.

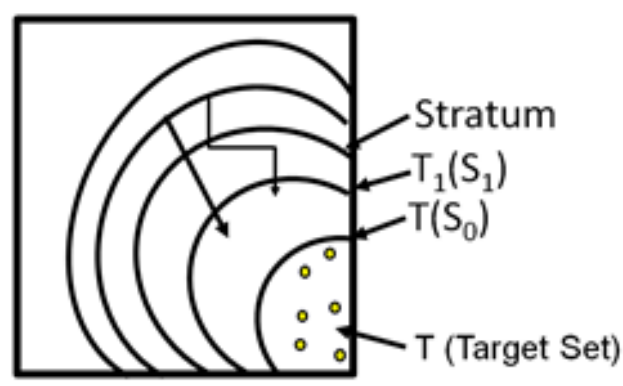

Fig. 1. Incremental enlargement principal [26].

If the target is not reachable, we incrementally enlarge the Target, or we incrementally enlarge the Stratum (for instance), through the use of granulation and/or quantization of the "Benefit" concept to reach to a finite state system [FSM]. This can be computerised and we intend to develop a proof of concept demonstrator.

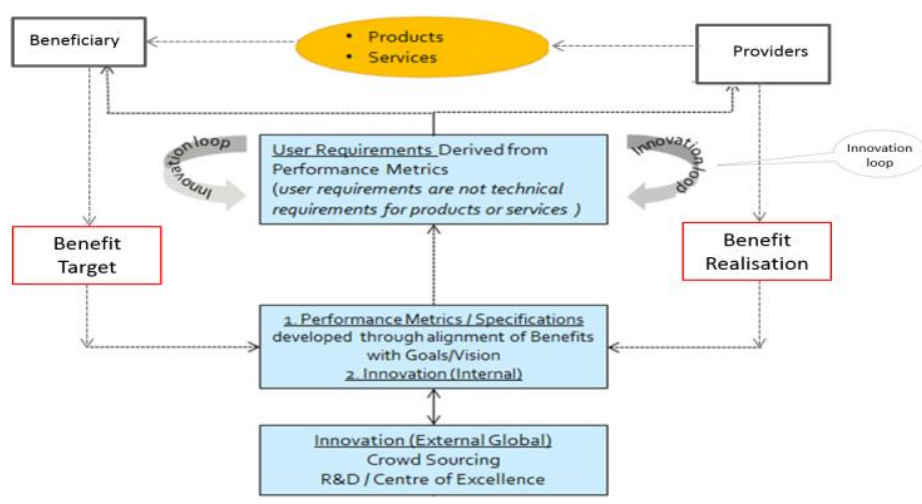

Fig. 2. Innovation-led benefits framework for ICT procurement. 
Part II: To foster benefit realisation for all the parties involved by fostering innovation among the parties via iterative innovation loop which allow continuous review and re-alignment of the benefit target and realisation to meet the changing organisational and end-user needs (Fig. 2).

In this framework, the Innovation loop is informed by the commercial best practice, research and crowed sourcing. In case of government IT procurement, this framework could be used for setting-up an innovation-led approach to collaboration between government, industry and academia for benefits realisation. This innovation-led benefits realisation framework, by considering the simple decision model in a highly-integrated choices and continuous improvement environment, supports collaboration of multiple stake holders via developing innovative solutions in an iterative loop.

\section{Conclusion}

In this paper, we presented IT governance challenges, and Benefit models used for IT governance. We identified key issues in implementing the Benefit Model for IT governance and we proposed defuzzification approach to help organization to understand Benefits and we proposed method to help with realization of Benefit. The future work includes IT enabled Benefit Realization Platform and cases studies for organization wide Benefit approach to IT governance.

\section{References}

[1] Sethibe, T., Campbell, J., \& McDonald, C. (2007). IT governance in public and private sector organisations: Examining the differences and defining future research directions. Proceedings of the ACIS (p. 118).

[2] Hoch, D., \& Payán, M. (2008). Establishing good IT governance in the public sector. McKinsey on Government (pp. 45-55).

[3] Wu, S.P.-J., Straub, D.W., \& Liang, T.-P. (2015). How information technology governance mechanisms and strategic alignment influence organizational performance: Insights from a matched survey of business and it managers. Mis Quarterly, 39(2), 497-518.

[4] Zhang, S., \& Le, F.H. (2013). An examination of the practicability of COBIT framework and the proposal of a COBIT-BSC model. Journal of Economics, 1, 5.

[5] Marquis, H. (2006). ITIL: What it is and what it isn't. Business Communications Review, 36(12), 49.

[6] Shang, S.S., \& Lin, S.-F. (2010). Barriers to implementing ITIL-a multi-case study on the service-based industry. Contemporary Management Research, 6(1), 53.

[7] Leitch, M. (2005). Why the COSO Frameworks Need Improvement. IRMI Update.

[8] Goldenson, D., \& Gibson, D.L. (2003). Demonstrating the Impact and Benefits of CMMI: An Update and Preliminary Results.

[9] Robinson, N., Lindsay, P., \& Pitman, A. (2000). Extending the Integrated Capability Maturity Model (CMMI) for Safety-related Applications. The University of Queensland: Software Verification Research Centre, School of Information Technology, Technical (Report No. 00-40).

[10] Dale, C., \& Anderson, T. (2009). Safety-critical systems: Problems, process and practice: Proceedings of the 17th Safety-Critical Systems Symposium Brighton: UK, February 2009, (pp.3-5). Springer Science \& Business Media.

[11] Weill, P., \& Ross, J.W. (2004). IT Governance: How Top Performers Manage IT Decision Rights for Superior Results. Harvard Business Press.

[12] Ward, J., Taylor, P., \& Bond, P. (1996). Evaluation and realisation of IS/IT benefits: An empirical study of current practice. European Journal of Information Systems, 4(4), 214-225.

[13] Remenyi, D., \& Sherwood-Smith, M. (1998). Business benefits from information systems through an 
active benefits realisation programme. International Journal of Project Management, 16(2), 81-98.

[14] Defence.gov.au. CIOG Defence-ICT-Strategic-Direction. Retrieved from the website: http://www.defence.gov.au/CIOG/_Master/docs/Defence-ICT-Strategic-Direction-2016-2020.pdf

[15] Kunal, M., Frederik, A., \& Jessica, B. (2016). Realising value from projects: A performance-based analysis of determinants of successful realisation of project benefits. Int. J. of Project Organisation and Management, 8(1).

[16] Andrew Lawrence, N., et al. (2013). Ensuring benefits realisation from ERP II: The CSF phasing model. Journal of Enterprise Information Management, 26(3), 218-234.

[17] Smith, D.C., Dombo, H., \& Nkehli. N. (2008). Benefits realisation management in information technology projects. in PICMET 08 - 2008 Portland International Conference on Management of Engineering \& Technology.

[18] Department of Treasury and Finance, V., Australia, Investment Management Standard version 5 - A Guide for Victorian government departments and agencies. (2013). Government Publication.

[19] Peppard, J., Lambert, R., \& Edwards, C. (2000). Whose job is it anyway? organizational information competencies for value creation. Information Systems Journal, 10(4), 291-322.

[20] Porter, M.E., \& Heppelmann, J.E. (2015). How smart, connected products are transforming companies. Harvard Business Review, 93(10), 53-71.

[21] Serra, C.E.M., \& Kunc, M. (2015). Benefits realisation management and its influence on project success and on the execution of business strategies. International Journal of Project Management, 33(1), 53-66.

[22] Peppard, J., Ward, J., \& Daniel, E. (2007). Managing the realization of business benefits from IT investments. MIS Quarterly Executive, 6(1).

[23] Peever, D.H., Robert,L., Mcdowell, P., \& Tanner, J. L. (2015). First principles review of defence - creating one defence, D.o. Defence, Editor. 1 April. Commonwealth of Australia: Canberra, Australia.

[24] Ghildyal, A., \& Chang, E. (2016). Realising value from it procurement: A conceptual model for alignment of organisational goals and benefits with user requirements 38th International Business Research Conference, Sydney.

[25] Ghildyal, A., \& Chang, E. (2016). Critical review of IT governance models and frameworks and challenges facing the public sector management. Information Systems Quarterly (submitted), 2016.

[26] Zadeh, L.A. (2016). Stratification, target set reachability and incremental enlargement principle. Information Sciences, 354, 131-139.

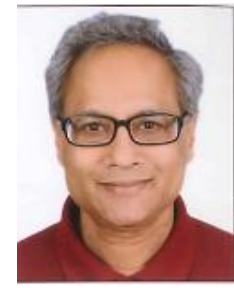

Amit Ghildyal has a bachelor's degree in engineering and an MBA, and is a certified procurement professional (MCIPS - UK). He is currently enrolled as a PhD candidate with UNSW Canberra under supervision of professor Elizabeth Chang and his research is on developing a new model for information governance in defence to address the impact of the rapidly changing digital services environment and First Principle Review on Defence Supply Chain. Mr. Ghildyal has worked with large global corporations across Asia-Pacific in a variety of operational and corporate roles, and functions including supply chain engineering and management.

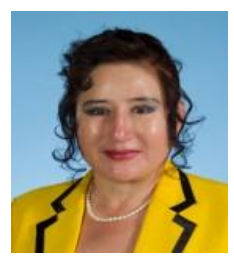

Elizabeth Chang is professor of logistics and canberra fellow at UNSW at Australian Defence Force Academy (ADFA). Professor Chang leads the Defence logistics research group at UNSW Canberra, targeting the key issues in Logistics ICT, big data management, defence logistics and sustainment, predictive analytics, situation awareness, IoT and Cyber-Physical Systems, Trust, Security, Risk and Privacy. In a 2012 article, she published in MIS Quarterly vol. 36 iss. 4, Professor Chang was ranked fifth in the world for researchers in Business Intelligence. She has delivered 52 Keynote/Plenary speeches largely at major IEEE Conferences and most recent in the areas of semantics, business 
intelligence, big data management, data quality and the like. Her academic achievement includes 24 competitive research grants, including 12 Australian Research Council (ARC) Grants worth over \$15 million. She has supervised/co-supervised $41 \mathrm{PhD}$ theses to completion, 21 Master theses and 16 Post-docs. She has published 7 authored books, over 500 international journal papers and conference papers with an H-Index of 40 (Google Scholar) and over 8,000 citations. 